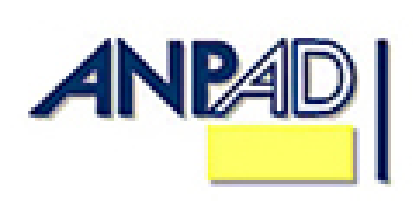

Disponível em

http://www.anpad.org.br/rac

RAC, Curitiba, v. 14, n. 2, art. 1,

pp.194-211, Mar./Abr. 2010

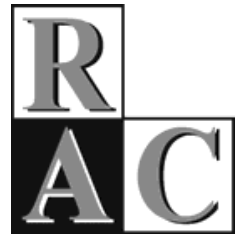

\title{
"Corpo e Alma" nas Organizações: um Estudo Sobre Dominação e Construção Social dos Corpos na Organização Militar
}

\author{
"Body and Soul" in Organizations: a Study of Domination and the Body's Social \\ Construction in the Military Organization
}

Alexandre Reis Rosa * Doutorando em Administração Pública e Governo pela EAESP/FGV. Professor da ESPM, São Paulo/SP, Brasil.

Mozar José de Brito Doutor em Administração pela FEA/USP. Professor do PPGA/UFLA, Lavras/MG, Brasil.

* Endereço: Alexandre Reis Rosa

Departamento de Planejamento, Organizações e Recursos Humanos - ESPM-SP, Rua Dr. Álvaro Alvim, 123, Vila Mariana, São Paulo/SP, 04018-010. E-mail: areis@espm.br

Copyright (C) 2010 RAC. Todos os direitos, inclusive de tradução, são reservados. É permitido citar parte de artigos sem autorização prévia desde que seja identificada a fonte. 


\title{
RESUMO
}

Este trabalho tem por objetivo discutir como ocorre o processo de construção social do sujeito militar e os mecanismos de controle subjacentes a essa socialização. Resultado de uma pesquisa de mestrado, a análise aborda o corpo como elemento central desse processo, devido ao seu caráter performático na atividade militar. Nesse sentido, autores como Pierre Bourdieu e sua articulação campo-habitus como elemento de reprodução do social, em conjunto com as reflexões de Michel Foucault sobre o poder disciplinar e as tecnologias de docilização dos corpos, nos ajudam a compreender como se processam esses corpos, a partir de uma tecnologização inerente à socialização militar. A metodologia utilizada foi o estudo de caso com a observação não-participante, entrevistas em profundidade e análise documental e de conteúdo. Com base nos resultados, concluímos que há uma variação nas formas de dominação, no sentido de privilegiar técnicas que vão desde uma pedagogia corporal para os soldados, até uma pedagogia moral para os oficiais, como principais instrumentos que visam, sobretudo, a uma espécie de dominação total do sujeito, ou seja, possuí-lo de corpo e alma na organização militar.

Palavras-chave: dominação simbólica; socialização organizacional; organizações militares.

\begin{abstract}
This paper aims to discuss how the process of social construction of the military individual occurs. The result of research for a Master's Degree, the analysis approaches the body as the central element of this process due to its manner of performing in military activities. In this regard, authors like Pierre Bourdieu and his field-habitus articulation as part of social reproduction, along with Michel Foucault's thoughts about disciplinary power and the technologies for docilization of bodies help us to understand how these bodies are processed from an inherent technologizing in military socialization. The methodology used was the case study with non-participant observation, in-depth interviews and documentary and content analysis. Based on the results, we find that there is a variation in the forms of domination in order to prioritize some techniques that range from body pedagogy (for soldiers) to oral pedagogy (for officers), as the main instruments that aim, above all, at a kind of total individual domination, to put it in a nutshell, to take over one's body and soul in the military organization.
\end{abstract}

Key words: symbolic domination; organizational socialization; military organizations. 


\section{INTRODUÇÃO}

Se a origem da teoria organizacional deve parte de seus pressupostos aos estudos de Max Weber sobre burocracia, então podemos dizer que, indiretamente, deve também à organização militar, uma vez que foi nessa seara que o teórico alemão buscou elementos para suas formulações, em particular no que tange à formalização, hierarquia e disciplina. Sendo essa última um exemplo de que "nenhuma prova especial é necessária para mostrar que a disciplina militar é o modelo ideal para a moderna fábrica capitalista” (Weber, 2002, p. 183). Suas conseqüências aparecem nos trabalhos de Taylor, Fayol e muitos outros fundadores da administração moderna; assim, desenvolver uma reflexão, a partir do campo militar, seria, de certa forma, retomar essa fonte e verificar o que ainda pode ser utilizado para compreender as organizações contemporâneas.

Ao desenvolver sua metáfora da organização vista como máquina, Morgan (1996) também utiliza a organização militar como fonte de práticas que influenciaram as teorias vinculadas à escola clássica da administração. Em meio a essa dinâmica de práticas militares, interessam-nos particularmente as relações de poder subjacentes ao controle dos indivíduos neste contexto. Da mesma forma que outros processos de gestão militar reverberam até hoje nas organizações (hierarquia, disciplina, formalização, etc.), acreditamos que os mecanismos de controle social seguem uma lógica similar. Nesse sentido, o presente trabalho tem por objetivo discutir como ocorre o processo de construção social do sujeito militar e os mecanismos de controle subjacentes a essa socialização, com técnicas que vão desde uma pedagogia corporal para os soldados, até uma pedagogia moral para os oficiais, como principais instrumentos que visam, sobretudo, a uma espécie de dominação total do sujeito, ou seja, possuí-lo de corpo e alma na organização militar.

Quanto aos procedimentos metodológicos, a pesquisa teve caráter qualitativo, com uso do método de estudo de caso, técnicas de análise documental e entrevistas em profundidade. A organização analisada foi um colégio militar do Exército Brasileiro e os sujeitos da pesquisa foram homens e mulheres militares, ocupando variados postos nessa organização. Por esse motivo, em vários momentos do texto, enfatizamos essa diversidade com o uso do o(a). Assim, deixamos claras as passagens que se aplicam tanto para os homens quanto para mulheres e aquelas que tratam especificamente dos homens.

Quanto à estrutura de apresentação, o artigo está dividido da seguinte forma: além desta introdução, na segunda parte seguem algumas reflexões sobre a relação individuo/sociedade, demarcando nosso entendimento desta dicotomia. Na terceira parte, discutimos o processo de socialização organizacional e as formas que ele assume na organização militar brasileira. Na quarta parte apresentamos os mecanismos de dominação do campo militar, representados pela hierarquia e disciplina, considerados como pilares institucionais e, finalmente, discutimos as formas de exteriorização com base nos julgamentos morais (alma) e expressões corporais (corpo) dos militares socializados.

\section{CAMPO E HABITUS: CONSIDERAÇÕES INICIAIS SOBRE A RELAÇÃo INDIVÍDUO/SOCIEDADE}

Na perspectiva sociológica desenvolvida por Bourdieu (1989, 1995, 1996a, 1996b, 1999, 2004, 2005), indivíduo e sociedade se conectam por meio do que ele denomina de habitus. Ou seja, um sistema de disposições duráveis que atua como princípio gerador e organizador das práticas e representações sociais. Tal espécie de máquina transformadora nos faz reproduzir as condições sociais de nossa própria produção, ou seja, refere-se a um processo de interiorização e exteriorização em que estruturas sociais se transformam em estruturas mentais e, num segundo momento, estas atualizam aquelas por meio das práticas: movimento de caráter dialético, cuja dinâmica ocorre de maneira circular (re)construindo e atualizando a realidade social. 
Ao se transformarem em estruturas mentais, as estruturas sociais exercem influência na forma como percebemos o mundo, delineando parte do nosso modo de agir, sendo exteriorizadas por meio do ethos, que corresponde a um conjunto sistemático de princípios ou valores em estado prático e de disposições morais que regulam a conduta cotidiana; e por meio da héxis, que corresponde a um conjunto de princípios interiorizados pelo corpo, tais como posturas e expressões corporais que são adquiridas (Bonnewitz, 2003). Ambas trabalham como esquemas de percepção e nos ajudam a (re)produzir nossas práticas. É pelo ethos que, por exemplo, nós julgamos se uma pessoa é humilde ou soberba, se votamos num partido ou em outro e até mesmo se gostamos mais de beber vinho do que cerveja. Pelo héxis corporal, assumimos as formas de uso do corpo, andando de cabeça erguida ou curvada, se gesticulamos ao falar, se falamos alto e até mesmo se devemos sorrir ou não, quando estamos numa relação com o outro.

Como história individual e grupal sedimentada no corpo, o habitus fornece ao mesmo tempo um princípio de socialização e de individualização: socialização porque nossas categorias de julgamento e de ação, advindas da sociedade, são partilhadas por todos aqueles que foram submetidos a condições e condicionamentos sociais similares; por isso podemos falar, por exemplo, de um habitus religioso, acadêmico ou militar; e individualização, porque cada pessoa, ao ter trajetória e localização única no mundo, internaliza uma combinação particular e incomparável de esquemas. Nesse sentido, podemos dizer que o habitus "é aquilo que confere às práticas a sua relativa autonomia no que diz respeito às determinações externas do presente imediato. [fazendo] do agente individual um mundo no interior do mundo" (Wacquant, 2005, p. 317, grifos no original).

Ainda sobre a noção de habitus, Wacquant (2005) procura esclarecer quatro pontos importantes: primeiro, o habitus nunca é a réplica de uma única estrutura social, pois seu conjunto de disposições, sobrepostas em camadas, tende a gravar e armazenar a influência dos diversos campos vividos pela pessoa ao longo de sua vida. Por conta disso, em segundo lugar, o habitus não é necessariamente coerente e unificado, mas revela graus variados de integração e clivagens, que resultam das condições irregulares que o produziram ao longo do tempo e, conseqüentemente, geram linhas de ação irregulares e, por vezes, incoerentes. Terceiro, o habitus não está necessariamente de acordo com o mundo social em que evolui. Por isso não podemos universalizar modelos de ação, sem considerar que eles apenas são válidos no caso em que as condições de produção sejam idênticas ou homólogas às condições de funcionamento. Caso contrário, o habitus pode falhar ou ter momentos críticos de perplexidade e discrepância. Por último, o habitus não é um mecanismo auto-suficiente para a geração da ação. Ele depende do estímulo externo e, por isso, não pode ser considerado isolado dos mundos sociais particulares - campos - dos quais evoluiu.

Uma análise completa da prática requer uma articulação dialética entre a gênese e as estruturas sociais do habitus e do campo. Sendo este último definido como um espaço estruturado relativamente autônomo com regras próprias de funcionamento e com suas próprias relações de força. Essa autonomia relativa está condicionada à existência de um corpo reconhecido de agentes consagrados, de procedimentos estimulados ou proibidos e da vinculação dos indivíduos a um tipo específico de atividade (Bourdieu, 1983).

Nesse sentido, a noção de campo nos ajuda a entender como a sociedade se diferencia e como ela é heterogênea. Ou seja, em cada campo social há uma dinâmica específica e, a partir dessas especificidades, podemos compreender, por exemplo, porque as relações sociais no campo econômico são diferentes das relações no campo militar que, por sua vez, diferem do que acontece em diversos outros campos sociais. Por se tratar de espaços estruturados, os campos possuem posições e estratos definidos, que independem da pessoa ou da organização em si, que ocupa essa posição. Na organização militar, por exemplo, a distinção expressa pela função de comandante de uma unidade, independe do militar que ocupa essa posição, pois se trata de uma posição que já existe na estrutura do campo e que requer determinados atributos - conforme as regras vigentes no campo - para que seja ocupada. Ou ainda, tomando como exemplo o campo econômico e a distinção de empresa do ano, cuja posição existe independentemente de qual empresa vai ocupá-la. 
Todavia, mesmo diante de tendências que particularizam os campos sociais, tornando-os relativamente autônomos e diferenciando a sociedade, existem, segundo Bourdieu (1983), tendências gerais que se aplicam a qualquer campo. São em número de três e delimitam as leis gerais dos campos: a primeira é o reconhecimento de um objeto de luta comum. Ou seja, em todos os campos existem capitais que são disputados por seus membros com vistas à movimentação e ocupação de posições de poder nesse campo. No rastro dessa primeira lei, a segunda exige que existam pessoas para jogar o jogo. Ou seja, o estado da relação de forças entre esses jogadores define - de forma dinâmica - a estrutura de um determinado campo, em que dominantes e dominados adotam estratégias de conservação ou de subversão da ordem simbólica com base nas suas posições, num momento especifico do jogo. A terceira lei geral é a unidade manifestada por seus agentes contra todo ataque que tente denunciar os interesses reais do jogo. Ou seja, um tipo de corporativismo dos que estão jogando, seguindo as leis do campo e disputando contra os que pretendem penetrar no campo desrespeitando as regras, impondo novos objetos de luta, ou buscando deslegitimar comportamentos definidos como legítimos pelos jogadores do campo. Tais jogadores, para que assim se caracterizem, precisam de um habitus correspondente ao campo em que se inserem. Por exemplo, no campo militar, exige-se a posse de um habitus militar; no campo religioso, um habitus religioso etc. Apenas quem incorpora o habitus próprio do campo tem condições de jogar o jogo e acreditar na importância de jogá-lo (Bourdieu, 1995).

Considerando o habitus militar como um exemplo de in(corpo)ração das estruturas sociais do campo militar, o princípio da socialização secundária, desenvolvido por Berger e Luckmann (1996), nos ajuda a compreender como os militares socializados nesse campo interiorizam suas estruturas, transformando-as numa estrutura mental capaz de orientar suas práticas, diferenciando-os de outros indivíduos; a referida in(corpo)ração ocorre por meio de um trabalho de inculcação da doxa - conjunto de opiniões naturalizadas no campo, como um ponto de vista que se apresenta e se impõe como universal, como auto-evidente, cuja composição está além do alcance do debate ou da elaboração (Bourdieu, 1996a) - realizado durante o contato inicial nos cursos de formação, nos quais ocorre a construção do que denominamos aqui de habitus militar. Todavia, a preservação, atualização ou subversão desse habitus depende principalmente da sua manutenção e reforço (ou enfraquecimento), quando o militar prossegue na carreira e passa a conviver com a dinâmica das organizações militares em que trabalha, reproduzindo os conteúdos aprendidos nesses cursos.

\section{MOdELANDO OS CORPOS: SOBRE A SOCIALIZAÇÃO ORGANIZACIONAL}

Segundo Berger e Luckmann (1996, p. 173), “o indivíduo não nasce membro da sociedade. Nasce com a predisposição para a sociabilidade”, isto é, depende de uma porta de entrada para que se torne membro de uma sociedade, o que na prática corresponde a um processo denominado pelos autores de socialização. Contudo, essa integração do individuo na sociedade ocorre em duas fases ao longo da sua vida: (i) a socialização primária, em que o indivíduo tem seu primeiro contato com o universo simbólico, socialização em que encontra seus outros significativos expressos pela interação com os pais e parentes próximos. Trata-se de um sistema de referências inicial, cujos conteúdos tendem a variar de acordo com o contexto de socialização. Traçando um paralelo com a dinâmica campohabitus, essa socialização primária se caracteriza como um tipo de habitus primário, que servirá de referência inicial para a interiorização de outros sistemas de referência resultantes da entrada do individuo em novos segmentos da sociedade (campos sociais).

No decorrer da vida em sociedade, outros conhecimentos são necessários em virtude das diferentes fases que ela envolve. Sendo assim, ao participar de novos espaços de interação, tais como a escola, o clube, a universidade, o local de trabalho etc. o indivíduo sofre a chamada (ii) socialização secundária, que envolve a interiorização de submundos específicos (ou, nos termos de Bourdieu, campos sociais específicos) determinados pela complexidade da divisão do trabalho e pela conseqüente distribuição 
social do conhecimento numa dada sociedade. É uma fase subseqüente ao processo de socialização primária.

Os processos formais de socialização secundária são determinados por seu problema fundamental, a suposição de um processo precedente de socialização primária, isto é, deve tratar com uma personalidade já formada e um mundo já interiorizado. Não pode construir a realidade subjetiva ex nihilo. Isto representa um problema, porque a realidade já interiorizada tem a tendência a persistir. Sejam quais forem os novos conteúdos que devam agora ser interiorizados, precisam de certo modo sobrepor-se a esta realidade já presente. Há, portanto, um problema de coerência entre as interiorizações primitivas e as novas. O problema pode ser de solução mais ou menos difícil, conforme o caso (Berger \& Luckmann, 1996, p. 187).

Em virtude dessa dificuldade, de inserir um tipo de habitus secundário por sobre o habitus primário, ocorre o que Wacquant (2005) denomina de inércia do habitus, isto é, a persistência da interiorização primária em se manifestar como matriz geradora das práticas diante de novas camadas do habitus, interiorizadas pelo processo secundário de socialização. Essa persistência da socialização primária pode ser compreendida a partir da noção de habitus clivado, utilizada por Bourdieu (2005) para explicar sua própria experiência como menino pobre no interior da França que, depois de ingressar no campo acadêmico, atinge a consagração como titular da cadeira de sociologia no tradicional Collège de France. $\mathrm{O}$ antagonismo destes dois momentos foi o grande fantasma na vida de Bourdieu, gerando clivagens na sua forma de ver e viver o mundo social.

Com vistas a minimizar (ou até eliminar) efeitos similares a este, torna-se necessário que haja uma Ação Pedagógica [AP] capaz de inculcar nos novos participantes do espaço social a dinâmica cultural em vigor, ou seja, a doxa.

Tratando-se da socialização militar, em que os novos membros estão sujeitos ao que Berger e Luckmann (1996, p. 207) denominam de "alternação", cuja dinâmica se baseia numa "transformação quase total, isto é, na qual o indivíduo 'muda de mundos"”, esse processo ocorre por meio de uma AP extremamente violenta do ponto de vista simbólico que, nas palavras de Bourdieu e Passeron (1982), busca matar o 'velho homem', gerando um novo habitus, ou seja, segundo Berger e Luckmann (1996, p. 212), trata-se de um processo em que "a biografia anterior à alternação é caracteristicamente aniquilada in toto".

No seio da organização militar, responsável pela socialização, essa ruptura e construção de um novo habitus visam a transformar o civil em militar por meio de um arbítrio cultural, responsável por transmitir aos novos membros o conjunto de valores, normas e padrões de comportamento necessários à manutenção da identidade e da integridade da organização (Brito \& Pereira, 1996). Em termos práticos, isso pode ocorrer por meio de uma série de estratégias de socialização, cujo ponto principal reside na domesticação dos novos membros de forma tal que se ajustem adequadamente ao novo espaço, tornando-se dóceis e úteis aos propósitos da organização. Todavia, não trataremos aqui dessas estratégias, nem do processo inicial de socialização, tendo em vista nosso interesse específico pela manutenção do habitus no decorrer da carreira dos indivíduos na organização militar.

Nesse sentido, Berger e Luckmann (1996, pp. 196-197) afirmam que o processo de socialização jamais se completa. "Estando os conteúdos que interioriza continuamente ameaçados em sua realidade subjetiva”, pois competem com outras realidades interiorizadas, devido à presença do indivíduo em múltiplos espaços de interação. Com efeito, existe a necessidade de conservação do habitus por meio de processos sociais, que não são radicalmente diferentes dos exercidos na socialização inicial. Assim, a manutenção da realidade subjetiva apresenta-se como tarefa contínua, ininterrupta e principalmente atrelada ao seu contexto correspondente, delimitado aqui pelas estruturas objetivas do campo militar: ser militar não depende apenas dos conteúdos inculcados durante o curso de formação, mas, sobretudo, da convivência no campo militar e do contato social com outra(o)s militares, pois "só é possível o indivíduo manter sua auto-identificação como pessoa de importância em um meio que confirma esta identidade” (Berger \& Luckmann, 1996, p. 205). 
Um pontochave nesse processo de socialização continuada é a presença de uma pedagogia do corpo na formação militar. De forma homóloga à formação do atleta no campo esportivo, aos militares, em certa medida, aprendem a usar o corpo seguindo uma lógica performática, que estaria no cerne de um bom desempenho das atividades militares, tornando este corpo uma arma (Wacquant, 2002). Em todos os níveis hierárquicos, particularmente nos mais subalternos da hierarquia (soldados), o aprendizado assume uma dinâmica em que

Há um modo de compreensão totalmente particular, em geral esquecido nas teorias da inteligência, e que consiste em compreender com o corpo. Há uma infinidade de coisas que compreendemos somente com o nosso corpo, aquém da consciência, sem ter palavras para exprimi-lo. [Deste modo] ... as práticas esportivas [e também as militares] são essas práticas nas quais a compreensão é corporal. Em geral, só se pode dizer: ‘Olhe, faça como eu’ (Bourdieu, 2004, p. 219).

Esse caráter mimético de aprendizagem do corpo pelo corpo se expressa bem nas instruções militares de ordem unida, maneabilidade, manejo de armas e treinamento físico, que são vistas como fundamentais na formação básica de todos os militares e tendem a ser ensinadas por meio de técnicas de demonstração. Sua fixação é dada pela repetição continuada durante a vida do militar após formarse e visam, sobretudo, a moldar o corpo de tal forma que se ajuste às normas e possa reproduzi-las dócil e performaticamente. Pois

há uma ligação entre o corpo e o que em francês nós chamamos de espirit de corps. Se a maioria das organizações, seja a Igreja, o Exército, os partidos, as indústrias, etc., dão tanto espaço às disciplinas corporais, é porque, em grande parte, a obediência é a crença, e porque a crença é o que o corpo admite mesmo quando o espírito diz não (poderíamos, nessa lógica, refletir sobre a noção de disciplina). ... A disciplina corporal é o instrumento por excelência de toda espécie de 'domesticação': sabe-se o uso que a pedagogia dos jesuítas fazia da dança. Seria preciso analisar a relação dialética que une as posturas corporais e os sentimentos correspondentes: adotar certas posições ou certas posturas é, sabe-se desde Pascal, induzir ou reforçar sentimentos que elas exprimem. O gesto, segundo o paradoxo do comediante ou do dançarino, reforça o sentimento que reforça o gesto. Assim se explica o lugar destinado por todos os regimes de caráter totalitário às práticas corporais coletivas que, simbolizando o social, contribuem para somatizá-lo e que, pela mimesis corporal e coletiva da orquestração social, visam reforçar a orquestração. A História do soldado lembra a velha tradição popular: fazer alguém dançar significa possuí-lo. Os 'exercícios espirituais' são exercícios corporais, e inúmeros treinamentos modernos são uma forma de ascese no século (Bourdieu, 2004, pp. 219-220, grifos no original).

Essa relação dos militares com o corpo é algo de suma importância para compreendermos o controle social nesse espaço. Todavia, o corpo e toda a simbolização que dele advêm não podem ser vistos de forma isolada, pois se articulam com outras categorias e, de certa forma, os atravessa em meio às relações sociais na organização militar. Assim, retomaremos essa questão em pontos subseqüentes da nossa discussão, estabelecendo uma interface do corpo com a dominação simbólica.

Retomando a questão da manutenção do habitus secundário e baseados nos trabalhos de Brito e Pereira (1996), Castro (1990) e Leirner (1997), assumimos aqui que essa manutenção do habitus, por meio das relações sociais no contexto militar, é norteada principalmente por duas categorias centrais que permeiam essas relações no cotidiano da organização militar: a hierarquia, que delimita quem manda e quem deve obedecer; e a disciplina, que assegura tal obediência. Ambas possuem uma relação de interdependência e são reconhecidas pela própria organização como pilares da instituição militar. Ao serem incorporadas, essas duas categorias operam uma lógica de mão dupla que se completa ao serem exteriorizadas por meio de práticas manifestas nas e para as relações, caracterizando a dinâmica do habitus militar. Todavia, antes mesmo de iniciarmos esse ponto, falaremos um pouco sobre a formação militar brasileira. 


\section{Os Tipos de Socialização na Organização Militar Brasileira}

Embora não seja nosso foco fixar a discussão na fase de formação, consideramos importante descrever resumidamente como ela ocorre. Afinal, o tipo e duração dessa formação inicial são importantes para compreendermos como, segundo Maanen (1989), os “corpos são processados" e o impacto disso no decorrer da vida militar após essa fase.

Na experiência brasileira, em particular no Exército Brasileiro, a formação militar ocorre segundo o público específico a ser processado. Isto é, diferem no formato e na duração conforme o nível hierárquico, o tipo de especialização e a condição profissional de cada militar, conforme a Tabela 1.

Tabela 1

\section{Tipos de Formação Militar}

\begin{tabular}{cccccc}
\hline Nível & Especialidade & Condição & Local & Tempo & Regime \\
\hline \multirow{2}{*}{ combatente } & carreira & AMAN & 5 anos & Internato \\
& & temporário & NPOR & 10 meses & Externato \\
\cline { 2 - 6 } oficiais & & IME & 5 anos & Externato \\
& \multirow{2}{*}{ técnico } & carreira & EsSEx, EsAEx & 10 meses & Externato \\
& & & SAREx & --- & Externato \\
& & temporário & OMs & 45 dias & Externato \\
\hline \multirow{3}{*}{ sargentos } & \multirow{2}{*}{ combatente } & carreira & EsSA & 10 meses & Internato \\
& & temporário & OMs & 2 meses & Externato \\
\cline { 2 - 6 } & \multirow{2}{*}{ técnico } & carreira & EsIE, EsSEx & 10 meses & Internato \\
& & temporário & OMs & 45 dias & Externato \\
\hline soldados & comb./técnico & temporário & OMs & 6 meses & Externato \\
\hline
\end{tabular}

Nota. Fonte: elaborado pelos autores com base nos dados secundários da pesquisa.

Em todos os níveis hierárquicos, temos a divisão entre a formação combatente e a formação técnica e, em cada especialidade, a divisão entre militar de carreira e militar temporário. No caso dos oficiais combatentes de carreira, ocorre o processo de socialização mais intenso e longo de toda a formação militar. Intenso, porque acontece em regime de internato e o conteúdo ministrado se alterna entre ensino fundamental (acadêmico) e profissional (militar), sendo esse último de caráter sobretudo prático, por meio de manobras militares e exercício de campo. Longo, porque ocorre num período de cinco anos ininterruptos. A organização responsável pela socialização é a Academia Militar das Agulhas Negras [AMAN], situada no município de Resende, RJ, cujo isolamento é comparado com uma bolha ou um mundo à parte.

"Lá dentro é aquilo: uma bolha, uma bolha quente! É assim que a gente costuma chamar. Porque não deixa de ser um mundo à parte né? Lá dentro você vive uma realidade... uma realidade diferente do que está acontecendo aqui fora, aliás você nem sabe o quê que tá acontecendo aqui fora” (Entrevistado 6).

Os jovens que ingressam na AMAN recebem o título de cadete e no final do curso são declarados Aspirante-a-Oficial, ingressando imediatamente na classificação militar com possibilidades de atingir o posto máximo da carreira, que é o de General-de-Exército. O ingresso se faz por meio de concurso público e pelo cumprimento de uma série de exigências, como, por exemplo, não ter completado 20 anos de idade no ano do concurso. A pouca idade é ponto importante nesse processo, na medida em que a ação pedagógica incidirá sobre um indivíduo jovem, com estruturas mentais suficientemente frágeis para uma eficaz alternação das estruturas subjetivas ou conversão do habitus. Assim, diante 
dessa identidade in statu nascenti a inculcação da doxa assume eficácia maior e mais violenta simbolicamente do que em outros processos de socialização. Nas palavras de um oficial formado na AMAN, o período de cadete representa um tipo de padronização.

“Quem estuda um pouquinho de psicologia sabe que aquilo lá é uma lavagem cerebral... porque tem que definir padrão... você pega um grupo heterogêneo de seiscentas pessoas e você tem que botar todas elas num padrão. A verdade é que na AMAN você sai ‘padronizado'. Se você pegar um cara da minha turma... tem diferenças ideológicas, alguma coisa de vivência anterior, mas na grande parte da personalidade ela é definida como um padrão. Ela é pa-dro-ni-za-da. Padronizada mesmo... é uma fábrica onde sai peças certinhas" (Entrevistado 5).

Com base nessa fala, torna-se possível identificar a preocupação do órgão formador em homogeneizar os cadetes por meio de um processamento padrão. Aliás, essa homogeneização, se apresenta objetivada na farda, na postura, no corte de cabelo e é reproduzida nos comportamentos, tais como a continência (que deve ser prestada de uma forma e não de outra) e a resposta, sem hesitar, ao chamado de um superior: "sim, senhor". Tudo previsto no regulamento em seus mínimos detalhes: trata-se de padronização de conteúdos que são inscritos nas mentes e nos corpos durante a formação. Não apenas dos oficiais formados pela AMAN, mas em todas as demais socializações, com diferenças em virtude da intensidade e da duração com que são inculcados.

No caso dos oficiais técnicos de carreira, esse processo se apresenta de variadas formas, conforme expõe a Tabela 1, porque, diferentemente dos oficiais combatentes, que são formados em regime de internato, os demais oficiais são formados em regime de externato: não sofrem o efeito bolha, descrito anteriormente e por isso tem seus corpos trabalhados com menor intensidade devido à formação de natureza técnica, isto é, não bélica. No caso dos oficiais temporários combatentes, há maior intensidade, mas um curto período de duração e nos oficiais temporários do quadro técnico, além da pouca duração, há também baixa intensidade, deixando-os numa situação menos militarizada que os demais oficiais. Por conta disso, muitos subordinados os vêem como militares bisonhos, isto é, com pouca habilidade para o exercício das missões militares.

A formação dos sargentos segue as mesmas particularidades da formação dos oficiais em termos de duração do curso e dos conteúdos ministrados. Afora a questão da idade, pois seja na formação de carreira ou temporária, há uma aproximação etária maior, tendo em vista a não-exigência de curso superior para as atividades desse nível hierárquico. No caso dos sargentos combatentes, há ênfase nas operações e exercícios de campo, aproximando-os da formação na AMAN. No caso dos técnicos, há ênfase nas técnicas voltadas para cada segmento de especialistas. Já para os temporários, a diferença está na duração do curso, que é inferior: dois meses para o combatente e 45 dias para o técnico.

Finalmente, a formação dos soldados ocorre a partir do Serviço Militar Obrigatório, em que os jovens na idade de 18 e 19 anos passam pela condição de recrutas e tem toda a sua formação na própria organização em que se incorporaram. Os conteúdos ministrados são eminentemente práticos e seu status é necessariamente de militar temporário, pois não há uma carreira de soldado no Exército, sendo necessário prestar concurso para sargento ou oficial.

Um ponto a ser ressaltado nos três níveis de formação (oficial, sargento e soldado) reside na forma com que o corpo é trabalhado em cada nível e tipo de formação: no âmbito dos oficiais, há ênfase maior na formação intelectual, embora os oficiais combatentes também sejam submetidos a exercícios físicos; há menos experimentação prática, devido à própria natureza das funções exercidas pelo oficial, normalmente voltadas à coordenação e controle de atividades desenvolvidas por subordinados. No caso dos sargentos, há equilíbrio entre atividades intelectuais e práticas, pois, pela a natureza das atividades desse segmento, sugere-se simultaneamente controle de subordinados e execução de algumas atividades. Já no nível dos soldados, predominam aspectos práticos, que os tornam elementos de execução das atividades militares. Assim, sua formação envolve muitos exercícios corporais e o aprendizado se faz por meio do "Olhe, faça como eu”, citado anteriormente.

Essa relação entre formação intelectual e corporal opera uma dinâmica complexa na organização militar, porque, se de um lado há uma valorização do intelectual em detrimento ao corporal, como é o 
caso dos cursos de Altos Estudos Militares que habilitam o oficial ao generalato; por outro, o corporal define claramente quem é, mais ou menos, operacional de acordo com sua performance nos exercícios de caráter bélico, conferindo aos corpos mais preparados (mais fortes) uma valorização desse capital físico, sendo até mesmo o ponto de argumentação sobre as limitações da mulher em combate, vista como fraca fisicamente para a atividade. Assim, o ponto de equilíbrio entre as duas dimensões seria o ideal nas atividades militares: uma posição privilegiada adviria da posse desses dois atributos que, em duas palavras, seria: forte e inteligente em contraste ao forte e burro ou ao fraco e inteligente - sendo esse último o menos valorizado entre os demais.

Independentemente do tipo de formação militar, após a formação inicial há um trabalho continuado de preservação e manutenção dos conteúdos incorporados, ou seja, de forma mais ou menos rigorosa, temos a existência de um trabalho de conservação do habitus militar por meio da hierarquia e disciplina, trabalho que será discutido a seguir.

\section{Os MECANISMOS DE DOMINAÇÃO: SOBRE O ESPÍRITO MILITAR}

Em todo o processo de formação militar, descrito anteriormente, busca-se, em última análise, construir uma forma de pensamento e ação característicos do que seja a profissão militar. Tais comportamentos possuem um fundo cultural que define um tipo de subjetividade denominado por Castro (1990) de "espírito militar", isto é, um conjunto de crenças, valores e comportamentos compartilhados pelos militares, um espírito incorporado naqueles indivíduos que usam a farda e servem à instituição. Tendo como ponto de partida a definição de que as forças armadas são "instituições nacionais, permanentes e regulares, organizadas com base na hierarquia e na disciplina" (Lei n. ${ }^{\circ}$ 6.880, 1980, p. 3, grifo nosso), assumimos a hierarquia e a disciplina como mecanismos privilegiados de organização desse espírito militar, sendo, para tanto, incorporadas pela subjetividade militar como matriz principal de orientação das práticas desses agentes no contexto militar.

Segundo Castro (1990), o principal efeito simbólico da socialização militar é a divisão dos mundos "civil” e "militar". Essa clivagem que delimita o nós e o eles acaba criando uma visão de comunidade militar, um tipo de 'espírito de corpo' entre seus membros, na medida em que prevalece o coletivo sobre o individual. Para Leirner (1997), o que media a relação entre estes dois mundos (civil e militar) seria a hierarquia, pois os militares tendem a estabelecer um sistema de equivalência entre a sua grade classificatória e as posições ocupadas pelos civis na sociedade. Há, portanto, autoridades civis equivalentes às autoridades militares. Tomando a escolaridade como elemento de comparação, os oficiais estariam no mesmo patamar hierárquico que os profissionais de nível superior das empresas públicas e privadas do mundo civil; os sargentos se comparariam aos profissionais de nível técnico e os soldados às funções auxiliares de baixa escolaridade. Na pesquisa de campo, essa equivalência foi identificada na divisão dos refeitórios, banheiros e alojamentos, que são uma objetivação dessas distâncias hierárquicas. São espaços de interação próprios para cada círculo hierárquico: oficiais, sargentos e soldados. Embora esses espaços tenham concretamente seu acesso livre com suas portas abertas, simbolicamente possuem barreiras de entrada que a hierarquia confirma.

Entretanto, longe de ser apenas um critério de classificação e equivalência, a hierarquia, segundo Leirner (1997, p. 53, grifo nosso),

é a base sobre a qual se exteriorizam cotidianamente sinais de respeito, honras, cerimonial, continências, ordens e comandos; tudo isso executado pelos membros da Força, cada qual em uma posição no interior da instituição, sem que ao menos precisem ter consciência de que, tomadas em seu conjunto, as diferentes condutas são manifestações particulares que necessariamente transitam por esse princípio regulador coletivo que é a hierarquia. Pode-se dizer, portanto, que a partir dela se espelham as relações e a visão de mundo militares. 
Dessa forma, a hierarquia, além de ser fator constitutivo do campo militar, está inscrito nos corpos, delineando relações e visões de mundo. No âmbito dessas relações, haveria então uma verticalidade subjacente a todas as situações, seja entre os militares, seja entre civis e militares, alguém sempre teria precedência sobre o outro. Isto é, no limite da classificação, ninguém estaria ao lado de ninguém, pois não há possibilidade de qualquer horizontalidade. Nos corpos, por sua vez, a hierarquia se funde com os modos de usá-la nessas relações verticalizadas. Está presente na fala humilde (voz baixa) ao se dirigir a um superior, na continência (saudação militar) instintivamente prestada ao cruzar com um superior, na forma enérgica de se dirigir a um subordinado e na expectativa de cobrar e de ser cobrado em relação a tais procedimentos. Por conseguinte, "olhar para a hierarquia significa olhar para um fenômeno capaz de traduzir um mapa desse mundo, entender uma conexão entre a fala e a conduta, entre o indivíduo e o grupo" (Leirner, 1997, p. 111).

Todavia, no campo militar, a hierarquia, na condição de geradora de práticas, "atua de maneira inconsciente, pois está naquela ordem de fenômenos coletivos que é capaz de transitar por diversos níveis, do particular ao geral” (Leirner, 1997, p. 108); depende de outro elemento fundamental, visto pelos militares como irmã siamesa: a disciplina, pois é esta que garante aquela, uma vez que todos os códigos de classificação e equivalência dispostos pela hierarquia para situar os indivíduos dentro de um lugar específico no campo militar - que pressupõe igualmente um comportamento específico (submisso ou autoritário) - somente se efetivam a partir de um corpo disciplinado: de acordo com Leirner (1997, p. 108) “'para que serve a disciplina?’ Diria que para cumprir a hierarquia”.

No regulamento militar, a disciplina aparece como elemento essencial para o funcionamento da organização militar, sendo definida como a "capacidade de proceder conforme normas, regulamentos e leis que regem a Instituição" (Decreto n. ${ }^{\circ}$ 4.346, 2002, p. 16, grifo nosso), ou ainda, como "a rigorosa observância e o acatamento integral das leis, regulamentos, normas e disposições, traduzindo-se pelo perfeito cumprimento do dever por parte de todos e de cada um dos componentes do organismo militar" (Decreto n. ${ }^{\circ}$ 4.346, 2002, p. 18, grifo nosso). A partir disso, podemos observar um esforço da instituição em pontuá-la como princípio de conduta militar, isto é, algo a ser incorporado e exteriorizado sob o risco de ser punido (na sua ausência) ou de ser elogiado (na sua presença). É, portanto, um elemento de controle e manutenção da hierarquia, pois opera por meio de um regime de punição e recompensa que garante que as leis que regem a Instituição sejam cumpridas e que os agentes do campo estejam, portanto, em conformidade com elas.

A recompensa por uma conduta disciplinada consta no Sistema de Avaliação Militar e conta pontos para a promoção. Já as punições por uma conduta indisciplinada podem variar desde uma simples advertência (considerada a forma mais branda de punir), passando pela repreensão, detenção, prisão, até a exclusão do militar a bem da disciplina (considerada a situação limite do sistema de punições). Com efeito, o militar que sofre a punição será sancionado materialmente, perdendo pontos para promoção; e, simbolicamente, tem sua moral abalada com os militares, estando a partir daí condicionado a não reincidir na transgressão que o levou à punição. Afinal, como o regulamento prevê, "a punição disciplinar objetiva a preservação da disciplina e deve-se ter em vista o benefício educativo ao punido e à coletividade a que ele pertence" (Decreto n. ${ }^{\circ} 4.346,2002$, p. 23, grifo nosso).

Em outros termos, o caráter educativo das punições nos remete ao poder disciplinar descrito por Foucault (1987), em que se busca a normalização dos agentes, fazendo-os funcionar de acordo com a norma, punindo os desviantes e recompensando os normalizados. Nesse sentido, a disciplina pode ser vista como uma técnica, com a qual se visa moldar padrões de comportamento por meio de uma pedagogia voltada principalmente para a manipulação do corpo, visto como elemento chave do poder disciplinar. Daí a importância da educação física no campo militar, na medida em que expõe o corpo a uma 'maquinaria', um conjunto de exercícios corporais (ordem unida, maneabilidade etc.) que visam a 'fabricá-lo' por meio do treinamento 'ortopédico', tornando-o submisso, dócil e útil. Obtendo dele "uma adesão que o espírito poderia recusar” (Bourdieu, 2004, p. 220).

Outra aproximação com o poder disciplinar se verifica na organização e codificação desses corpos no espaço estrutural do campo militar, o que facilita a identificação dos sujeitos a serem normalizados e vigiados. Nesse momento, de algum modo, voltamos à hierarquia; talvez por isso a relação siamesa 
ajuda nessa organização, na medida em que estabelece o lugar de cada um na cadeia de comando e a distância desse um em relação aos outros. Em sua forma objetivada, essa localização reside nos símbolos físicos representados pelas instalações físicas (alojamentos, banheiros e refeitórios) e pela farda (insígnias, medalhas etc.), que separam cada subgrupo da cadeia de comando em círculos hierárquicos de convivência, nos quais se sabe exatamente quem vigia e quem deve ser vigiado, quem pune e quem deve ser punido, quem manda e quem deve obedecer. Em sua forma subjetiva, ou seja, incorporada, a localização reside numa identidade de classe que organiza dominantes e dominados separadamente, gerando barreiras simbólicas, vistas como intransponíveis, sob o risco de ser promíscuo e/ou de ser julgado negativamente por não observá-la como uma norma de convivência militar. Em conseqüência, mais uma vez o pêndulo volta para a disciplina, pois, segundo Foucault (1987, p. 133), “a disciplina, arte de dispor em fila, é a técnica para a transformação dos arranjos. Ela individualiza os corpos por uma localização que não os implanta, mas os distribui e os faz circular numa rede de relações”. Sendo essa rede determinada pelas classes (oficial, sargento, soldado), isto é, nível hierárquico, daí novamente a hierarquia, depois a disciplina e assim sucessivamente, ad infinitum.

Esse constante devir entre hierarquia e disciplina caracteriza sua interdependência e sua forma de incorporação no habitus militar, uma vez que se reforçam mutuamente na construção do corpo disciplinado, que também é hierarquizado. Assim, o campo militar garante sua conservação por meio dessa adesão inconsciente da norma. A seguir exemplificamos como esse habitus se manifesta e ganha corpo no universo militar.

\section{De “Corpo e Alma”: As Disposições DurÁVeis da SOCIALIZAÇÃo Militar}

Na condição de princípio gerador e organizador das práticas e representações inerentes ao campo militar, o habitus militar emerge a partir da exteriorização de disposições morais que regulam a conduta cotidiana por meio do ethos militar e de princípios interiorizados pelo corpo por meio de seus usos em atividades ligadas à postura, gestos, verbalizações etc. definidos como a héxis militar. Embora apresentados aqui de forma separada, apenas como recurso analítico, vale ressaltar que são categorias correlatas na medida em que operam necessariamente juntas na formação de esquemas de percepção capazes de delinear a forma com que os militares se movimentam nas relações entre eles, entre eles e o campo militar e entre o campo militar (por meio deles) e o mundo exterior.

\section{O Ethos Militar: as Exteriorizações da "Alma"}

Com base nos tipos de socialização militar que discutimos anteriormente, observamos uma forma bastante peculiar de exteriorização de julgamentos e visões de mundo, delineando, com isso, algumas tendências gerais do ethos militar. Vejamos este primeiro relato:

"Parece que o Exército ali é um mundo, ... aí quando abre aquele portão, aí que a gente vê a realidade. O pessoal normal, usando camiseta, é bonito. Eu estranhei em ver as pessoas sorrindo, com cabelo comprido, a gente vê homem de cabelo comprido, estranha. É totalmente diferente. Depois eu já vi tanto, que incorpora a área, a tradição, a hierarquia, a disciplina” (Entrevistada 7).

Fica evidente nesse relato a idéia de identidade contrastiva entre o mundo militar e o mundo civil. Particularmente, quando a depoente diz: "o Exército ali é um mundo"; ela estabelece a referida demarcação e, com base nela, descreve as principais diferenças que lhe chamam a atenção: "pessoal normal, usando camiseta”, em contraste com militares que usam farda; "as pessoas sorrindo", em contraste com o perfil sisudo dos militares; e "homem de cabelo comprido", em contraste com o cabelo sempre curto do homem militar. Todas essas oposições confirmam a fronteira simbólica entre os 'mundos' e reforçam o sentimento de comunidade militar. Desse modo, em outras situações do 
cotidiano, a depoente poderá mobilizar todas estas elaborações na hora de julgar o quê (ou quem) faz parte do Exército ou do mundo civil - dos paisanos, conforme o linguajar militar.

No entanto, outras injunções podem advir desse contraste entre os mundos militar e civil. Operando uma espécie de totalização de um seguido da neutralização de qualquer influência do outro sob o agente que neles circula.

"Uma coisa a gente aprende na área militar: você é militar 24 horas, não é assim: tu está no quartel é militar, está na rua é civil. Não é assim. Tu é militar estando fardado ou não, estando na China, em qualquer lugar você é militar. 'Até debaixo d'água', como alguns costumam dizer. Então você é sempre militar... mas tu tem que conviver não só com a sargento ..., mas também com a civil .... Que nem do jeito que se escreve: na hora que você for assinar, você vai assinar Fulana da Silva, tracinho, terceiro sargento. É tua função, é tua profissão. Então isso vai servir para te carregar. E isso muda a pessoa para melhor, pra quem é fraca, ela consegue ver que ela é forte... dá aquela força de poder quebrar seus limites, coisa que no mundo aí fora não é muito valorizado" (Entrevistada 7).

Embora permaneçam demarcados, sob outros nomes, os mundos do quartel e da rua, não há um sujeito correspondente a cada um deles. Há apenas o militar. Uma identidade que não cessa no tempo, porque está ativa $\mathbf{2 4}$ horas e não se modifica no espaço porque em qualquer lugar, na China e até debaixo d'água se é militar. Além disso, torna-se uma marca, uma assinatura registrada com tracinho, terceiro sargento que, ao fim e ao cabo, servem para te carregar caracterizando-se como aquela força de poder quebrar seus limites; mas que no mundo aí fora não é muito valorizado. Ao estabelecer esse tipo de conexão entre a identidade civil e a militar com a prevalência desta sobre aquela, opera-se muito mais do que um ajuste entre subjetividades; ocorre o que Berger e Luckmann (1996) chamam de "alternação" e Bourdieu e Passeron (1982) de "conversão" do habitus. Assim, observamos um processo de totalização do habitus militar e a neutralização do habitus civil (ou primário), cujo resultado é percebido pela depoente como uma saída pra quem é fraca. Essa nova identidade, quando interiorizada, constrói a matriz de julgamentos que serão organizadoras das práticas de uma forma particular em todos os domínios da vida social.

"O militar tem um método. Como eu te falei, o cara é formatado... então todos que fazem Academia AMAN se dizer que não, está mentindo... porque é inconsciente. O cara pode até sair revoltado da Academia com o sistema... mas inconscientemente ele faz o método. Na AMAN a lavagem cerebral é no método ... você sai lavado no método. Você faz tanta patrulha, tanta patrulha que não adianta... qualquer coisa que você vai fazer na vida, viagem de férias, compras no supermercado, etc. você usa o método de patrulha [risos]. Mas por que isso? Porque são quatro anos fazendo a mesma coisa, repetindo, repetindo a mesma coisa... daí você acaba incorporando entende?” (Entrevistado 5).

A matriz organizadora das práticas é denominada no relato acima como um método, ou seja, uma forma particular de agir em qualquer coisa que você vai fazer na vida. Nesse caso, o processo de alternação ou conversão do habitus, reconhecido pelo depoente como "lavagem cerebral", visa, sobretudo, inculcar, por meio de um longo ("quatro anos fazendo a mesma coisa") e intensivo ("você faz tanta patrulha, tanta patrulha...”) trabalho pedagógico, um procedimento padrão diante de situações não padronizadas, isto é, situações do cotidiano. Desse modo, cria-se um sujeito previsível cujo comportamento, mesmo revoltado com o sistema, estará condicionado de um modo e não de outro, contribuindo com um controle social mais eficaz, pois se trata de um corpo disciplinado, um corpo docilizado (Foucault, 1987). O que o aproxima muito da norma e, de certa forma, de uma rigidez maior diante de situações de instabilidade ou mudanças bruscas.

Quanto às exteriorizações acerca da hierarquia, o relato abaixo ilustra como ela aparece nos julgamentos sobre esta categoria.

“Eu não esqueço disso nunca. É aquela questão: onde estou nessa cadeia hierárquica, quem me deve de alguma maneira esse respeito hierárquico e a quem eu devo. Tenho isso muito claro pra mim, na forma que eu exerço minhas funções sabe? E eu faço questão disso... faço mesmo. Porque se desde o primeiro momento você não se coloca assim... vira aquela palhaçada: 'ah, é mulher, não precisa continência'... 'não precisa chamar de senhor’, coisa e tal. Por isso eu faço questão, faço mesmo” (Entrevistada 5). 
Nesse último relato, temos um exemplo de como a hierarquia se manifesta para situar o indivíduo na rede de relações do campo militar. Porém muito mais do que apenas situá-lo, delimita também seu lugar nas relações de poder, na medida em que deixa muito claro quem manda e quem deve obedecer nessa rede de relações. E ainda, justamente por localizar o poder que circula na relação, impede que vire 'palhaçada' e que seja banalizado pelos subordinados durante o contato com o sujeito mandante que, nesse caso, é uma mulher. Por isso a depoente deixa claro: “eu faço questão, faço mesmo”.

Quanto à disciplina, muitos relatos giram em torno do comportamento do sujeito militar diante das normas, pois há certo consenso sobre a importância delas nas atividades diárias (pessoais e profissionais) e principalmente sobre seu papel no cumprimento da hierarquia. $\mathrm{O}$ relato a seguir ilustra essa exteriorização:

“A gente deve ser disciplinado pra tudo. Não só a parte que confere em fazer o certo, a coisa certa, não. Devemos ser disciplinados no horário, nos nossos horários... ah, tal hora tenho que fazer minha educação física, tal hora... tipo de oito as dez da noite eu tenho que fazer meu estudo, tal hora... e assim vai. Ter disciplina de horário e tentar ao máximo passar isso pro subordinado. E... é isso... olha aí as pessoas bem sucedidas na vida... são o que são porque tem esse negócio dos horários, de acordar sempre no mesmo horário, almoçar no mesmo horário" (Entrevistado 6).

A ênfase do depoente no cumprimento de horário em atividades rotinizadas como "tal hora tenho que fazer minha educação física”, "fazer meu estudo" e ainda se preocupar em "passar isso pro subordinado", nos remete a uma característica das instituições totais descrita por Goffman (1971), relacionada à vida fechada e formalmente administrada muito comum nas escolas de formação militar, em particular na AMAN, onde "todas as fases das atividades diárias são programadas dentro de linhas estreitas, uma atividade conduzindo no tempo predisposto para a próxima” (Goffman, 1971, p. 305) e os horários são burocraticamente organizados. Devido à exposição a rotinas dessa natureza durante a socialização militar, ocorre uma incorporação desse esquema, prolongando-se depois de concluído o curso. Conduzindo nosso depoente a reproduzi-lo como uma expressão da disciplina, de uma disciplina responsável pelo êxito das "pessoas bem sucedidas na vida”.

Finalmente, um depoimento que nos chamou a atenção refere-se a uma abordagem da hierarquia e da disciplina, com base em julgamento peculiar, dotado de certa plasticidade que beira a 'malandragem', descrita por DaMatta (1996) como um recurso de navegação social, utilizado em sociedades relacionais como a nossa.

“Essa questão de hierarquia e disciplina, eu acho que estão muito relacionadas com quem você está falando
... vou dar um exemplo: Pega lá o soldadinho que está, digamos assim, no nível mais baixo da hierarquia.
Depois que passa o período básico ele começa a pegar os bizús, ele já age no macete... se alguém chama ele:
‘soldado, vem cá!' ele pára e olha. Se for um soldado antigo ele vira e diz: ‘ah, vem cá você negão’... se for
um cabo, ele já grita de longe: ‘o que o senhor quer?’... se for um sargento, ele se desloca andando até o
sargento e diz: ‘pois não, senhor’... mas se for um oficial, principalmente se for o chefe da seção dele ou o
comandante de companhia, então ele vem correndo igual uma flecha, pára na posição de sentido e diz:
‘pronto, senhor!’. Mas eu te pergunto: por que ele age assim? De forma diferente com cada um que chama?
Se são todos mais antigos do que ele? Te digo porque. É porque ele já tem noção das conseqüências... um
outro soldado não pode fazer nada contra ele, digamos assim disciplinarmente, né? O cabo já poderia fazer
uma parte pedindo punição, mas normalmente isso morre na casca. O sargento já pode puni-lo se for
sargenteante ou se for adjunto coisa e tal... e o oficial, ele tem certeza que poderá punir, às vezes até expulso,
dependendo do caso. Do mesmo modo, o sargento e o oficial são aqueles caras que dão uma força numa
dispensa, numa troca de serviço, num engajamento... enfim, rola uma certa malandragem por trás do
cumprimento de ordens... as coisas não são cor-de-rosa como diz o regulamento, sabe? Na prática isso é
muito relativo... ocorre em todos os níveis, não só com o soldado” (Entrevistado 8).

O "com quem você está falando" descrito no relato caracteriza o ponto-chave das atitudes adotadas pelo soldado diante do chamamento de um suposto superior. No campo militar - diferente do que DaMatta (1996) descreve em sua abordagem sobre as estratégias de navegação social em nossa sociedade, cuja pergunta você sabe com quem está falando? opera como rito utilizado para demarcar posições ou afiliações sociais de um agente em dada relação, em virtude da farda e suas insígnias de identificação, você sempre sabe com quem está falando (Leirner, 1997). Justamente por isso, torna- 
se possível realizar o cálculo de conseqüências que o soldado do relato faz diante dos seus interlocutores.

Desse modo, o ethos militar - como faceta moral do habitus militar - além de reproduzir aspectos específicos do campo militar, reproduz também o contexto mais amplo disposto pela cultura brasileira e seus traços, como o da 'malandragem' de se postar estrategicamente numa relação hierárquica tal qual o soldado do exemplo acima. Nessa interseção entre os níveis organizacional e social, percebe-se que, ao falarmos de um campo militar, estamos falando, sobretudo, de um campo militar brasileiro. Com particularidades da nossa cultura articuladas com características universais da instituição militar em si. No próximo item fechamos essa breve descrição do habitus militar apresentando sua dimensão corporal e como os usos desse corpo são influenciados pelas disposições do campo militar.

\section{A Héxis Militar: as Exteriorizações do "Corpo"}

O processo de incorporação das estruturas sociais pelo sujeito ocorre com a inscrição nas mentes e nos corpos, formando o habitus. No item anterior vimos o resultado dessa inscrição na alma dos agentes militares. Agora veremos a força dessa inscrição nos corpos. Lembrando que o corpo e todos os seus usos, condicionados pelo habitus, assumem grande importância no campo militar, tendo em vista o caráter performático desse corpo.

Nesse sentido, o habitus militar condiciona o corpo a assumir gestos, verbalizações e movimentações que, muitas vezes, escapam ao controle do próprio sujeito, sendo exteriorizados de forma inconsciente, flagrante e, na maioria dos casos, inevitável.

"Eu acho que só falava quando alguém dava autorização. Eu estava sempre na posição de sentido, sempre eu estava até que alguém mandasse: ‘Não, pode ficar descansada, pode ficar a vontade’. Então, eu aprendi isso assim, sempre deixava o mais antigo [superior hierárquico] falar e já ficava na posição de sentido. Era sentido pra cá, sentido pra lá que quando a gente chegou aqui, o comandante falava: 'Menina, relaxa! Porque não é tanto assim'. Aí acho que foi moldado assim. Como algo depositado em nossa cabeça, um monte de coisas que na verdade nem era. Acho que por isso eu era extremamente tensa. Eu prestava continência pra todo mundo... porque a gente também não entra sabendo cada posto... então assim, com certeza, tinha que prestar continência pra soldado, pra cabo... alguém olhava sério pra mim já ganhava uma continência [risos]” (Entrevistada 2).

A idéia de inculcação por meio de um trabalho pedagógico fica evidente, quando a depoente interpreta seu condicionamento de estar "sempre na posição de sentido" como "algo depositado em nossa cabeça". De fato, foi isso que ocorreu ao realizarem um treinamento ortopédico desse corpo, condicionando-o a só falar "quando alguém dava autorização" e a se postar num constante estado de tensão diante dos superiores, a ponto de um deles dizer "relaxa!”. A mudança no uso do corpo fez com que a depoente agisse por reflexo, como um ato condicionado que o corpo executa instintivamente, na medida em que, ao perceber qualquer olhar sério, essa pessoa "já ganhava uma continência", mesmo sendo um subordinado que, pelo regulamento, não faria jus ao cumprimento.

Outro ponto importante relacionado à hexis corporal é a relação dos usos do corpo com o uniforme militar. Pois há um tipo de alinhamento corporal com a farda. Isto é, o militar deve seguir as padronizações estipuladas pela instituição, tais como cabelo, unhas, etc.

\footnotetext{
"Você tem que vestir o que eles querem, você não pode pintar a unha do jeito que você quer, você não pode usar o brinco que você quer, você não pode se pintar muito do jeito que você quer, você não pode usar sandália, só tem sapato pesado e coturno... então, essas coisas são... os padrões. Você tem que se padronizar, então, essa é a pior... eu acho que é o mais difícil, você deixar de ser o que você realmente é, pra você ser o todo, você incorporar, realmente, ao grupo, porque todo mundo tem que ser, entre aspas, igual. Mas você não é igual não! Cada um é cada um, se eu gosto de rosa, eu uso rosa, meu celular pode ser rosa, mas minha bolsa não vai poder ser rosa, minha camiseta não vai poder ser rosa, não vai poder combinar... tem que usar o que está previsto, então se o sapato te machuca, se o coturno não tá bom, eles não importam, tem que equipar do jeito que é previsto” (Entrevistada 6).
} 
Observamos que existem exigências quanto à estética corporal que não permitem variações. Como mostra a depoente há uma padronização que extrapola o uniforme e busca uma padronização também no uso de maquiagem, apresentação de unhas e bijouterias. Pelo que verificamos no Regulamento, de fato existe tal padronização, pois a regra chega a fazer menções sobre a descrição da apresentação individual que seria o "você não pode se pintar muito" mencionado pela entrevistada.

A idéia de padronização dos corpos em que as pessoas têm que deixar de ser o que você realmente é para ser o que a instituição autoriza, reflete a alternação que está presente também nas exteriorizações do ethos militar. Contudo, aqui ela ganha destaque por estar vinculada ao uniforme, levando-nos à idéia limite de o uniforme assumir um status de segunda pele, como algo que se transporta do plano simbólico para o real, na medida em que se torna elemento de cobrança nas relações superior-subordinado. Desse modo, o ponto chave da padronização que deve ser incorporado pelos militares tem seu ponto de partida no uniforme, cuja padronização aparece de forma muito clara no regulamento de uniformes. Assim, a farda exerce forte influência sobre o corpo, modificando-o simbolicamente, identificando-o na escala hierárquica. Agarrando-se ao corpo de uma forma que, mesmo não utilizando o uniforme de maneira material, o militar se sente fardado simbolicamente.

“É difícil dissociar... mesmo nas atividades pessoais. Antes eu era uma pessoa mais solta, podia sentar na calçada pra esperar o ônibus, me encostar na parede, podia... enfim, agora não, agora não pode! Mesmo que eu esteja em trajes civis, eu não tenho mais essa espontaneidade. ... a gente paga um preço por essa rigidez, por essa disciplina que você pode ser cobrado... essa consciência de quem eu sou sabe? Não como indivíduo, mas como profissional, do papel profissional que você exerce. É algo que, digamos assim, te condiciona a agir diferente de antes” (Entrevistada 5).

No relato fica evidente a mudança de comportamento e as restrições dessa mudança. A consciência de que a profissão não permite "sentar na calçada pra esperar o ônibus" ou "encostar na parede" "mesmo que esteja em trajes civis" demonstra o condicionamento $\mathbf{2 4}$ horas que citamos no item anterior sobre o ethos militar. Aqui esse ethos se traduz numa héxis, na medida em que o uso do corpo fica condicionado apenas às ações autorizadas pela norma, porquanto, ao mencionar que o militar deve "ser discreto em suas atitudes, maneiras e em sua linguagem escrita e falada" (Lei n. ${ }^{\circ}$ 6.880, 1980, p. 28), o regulamento não especifica quais atitudes e maneiras são ou não discretas, deixando que as interpretações sejam feitas pelo universo simbólico militar, que tende a incidir sobre o corpo que é ponto chave da disciplinarização do sujeito. Com efeito, paga-se "um preço por essa rigidez, por essa disciplina". Em adição, a idéia de vigilância aparece no relato, pois o uso correto do corpo "pode ser cobrado" a qualquer momento, seja pelos superiores, seja pela "consciência de quem eu sou" que, nesse caso, opera como uma autodisciplina, um controle próprio das ações no limite da norma.

Outro ponto de influência na hexis são os procedimentos normativos que regulam a convivência entre os militares. Análogo ao "não poder encostar na parede" uma série de injunções tácitas operam nos limites do corpo, condicionando-o a agir de maneira ortopédica em determinadas situações.

“Aqui você é cobrado pro serviço, então, você tem que levantar a mão para o superior, você tem que pedir permissão pra entrar nos lugares, se ele está conversando você tem que esperar, não pode interromper, então, assim, é uma questão de educação, mas lá fora você não está acostumado com isso, você pode interromper... você tem a liberdade... então, é mais isso” (Entrevistado 8).

Alguns procedimentos como "pedir permissão pra entrar" fazem parte do regulamento militar; porém outras ações como não interromper fazem parte da norma tácita. Todavia, em ambos os casos, o corpo tende a se portar de acordo com a norma, seja ela regulamentar ou tácita. Por estarem inscritas nos corpos, essas normas de conduta não respeitam as fronteiras entre o mundo civil e militar e tendem a se manifestar em outros campos sociais que o sujeito porventura venha a freqüentar. Conforme o relato a seguir:

"Uma vez na faculdade eu estava apresentando um trabalho e de repente eu adiantei um slide a mais na apresentação e comecei a explicar o que estava lá na tela... até que eu me toquei que tinha pulado um. Então eu olhei pra turma e falei 'última forma, não é esse'. Cara, naquele momento o pessoal congelou, sabe? Parecia que era um filme e a imagem parou...[risos] daí eu me dei conta que o pessoal não sabia o que era... o que significava ‘última forma’ [significa mais ou menos um aviso para desconsiderar o que foi dito e retornar ao 
momento inicial ou anterior àquele] que é uma gíria nossa aqui do quartel... e eu pensei: 'putz como eu fui falar isso... como pude...’ mas nessa hora não adianta, mesmo estando na faculdade, num outro lugar você deixa essas coisas escaparem...você começa a falar e gesticular como se tivesse aqui no quartel dando uma instrução pro soldado, sabe? O paisano até gosta porque você impõe uma postura, tem a voz firme, olha no olho deles coisa e tal... mas na hora que você solta um ‘última forma' desses... aí a sua casa cai [risos]” (Entrevistado 8).

Neste relato, o uso não-intencional da gíria militar no mundo civil nos mostra que "nessa hora não adianta, mesmo estando na faculdade, num outro lugar você deixa essas coisas escaparem” o que reflete a impossibilidade de o depoente conter a exteriorização do habitus militar justamente por ser uma disposição durável que se inscreve no corpo, gerando práticas socialmente condicionadas: é algo que “o corpo admite mesmo quando o espírito diz não” (Bourdieu, 2004, p. 219).

\section{À GUISA DE CONCLUSÃo}

Nosso objetivo neste trabalho foi discutir o processo de construção e manutenção da subjetividade militar, definida aqui como um tipo de habitus militar, destacando o corpo como epicentro desta construção e principal instrumento de efetivação da dominação simbólica. Para tanto, iniciamos argumentando que a relação entre indivíduo e sociedade ocorre por meio do conceito de habitus que, na perspectiva sociológica bourdieusiana, se caracteriza pela dialética entre estruturas sociais e mentais, formando a matriz geradora das práticas cotidianas. Com base nessa perspectiva, argumentamos que a socialização militar opera um tipo de alternação ou conversão desse habitus, na medida em que procura substituir sua forma primária pela secundária, representada aqui pela subjetividade militar.

As conseqüências dessa alternação emergem na forma como os militares exteriorizam seus julgamentos e na forma como utilizam seus corpos; este uso do corpo assume caráter performático, pois deve operá-lo como arma, tendo em vista a missão bélica que norteia a organização. No entanto, o grau de belicosidade desse corpo, bem como o grau de incorporação dessa lógica, depende da intensidade e da duração com que este corpo é trabalhado, ou seja, o tipo de construção que esse corpo sofre durante a fase de formação militar nos diversos estabelecimentos de ensino.

Os padrões obtidos nessa formação tendem a se reproduzir por meio de duas categorias basilares na instituição militar: a hierarquia e a disciplina. A primeira busca selecionar e posicionar os corpos dentro de uma cadeia hierárquica facilmente identificável, em que se sabe com precisão quem deve vigiar e quem deve punir. Para isso a disciplina transcorre como elemento central de manutenção dessa hierarquia, pois se encarrega de docilizar esses corpos, dando-lhes um tratamento ortopédico necessário ao seu uso performático e, principalmente para que ele se comporte de acordo com a norma.

Assim, o campo militar organiza sua dinâmica de relações sociais produzindo indivíduos altamente previsíveis, cujas reações estão condicionadas ao que é tido como certo neste espaço. Embora nossos resultados sejam específicos ao campo militar, tendo em vista a noção explícita de hierarquia e disciplina, acreditamos que, assim como Weber, as proposições aqui apresentadas sejam úteis também para pensarmos os processos de dominação simbólica existentes nas organizações contemporâneas: mesmo não sendo organizadas explicitamente dessa forma, possuem mecanismos altamente sofisticados de aliciamento e cooptação da subjetividade humana, ou seja, injunções que se inscrevem tanto na alma, com os julgamentos morais que realiza, como no corpo, com usos que a pessoa faz, ou não faz, desse corpo, caracterizando um tipo perverso de dominação.

Portanto, pensar esse processo no mundo militar pode ser um recurso heurístico para pensarmos analogamente o mundo civil, trazendo à tona esse poder invisível capaz de obter o equivalente do que é obtido pela força, perpetuando as barreiras que oprimem a subjetividade humana de expressar seus desejos e anseios mais originais.

Artigo recebido em 31.05.2008. Aprovado em 06.04.2009. 


\section{REFERÊNCIAS BIBLIOGRÁFICAS}

Berger, P., \& Luckmann, T. (1996). A construção social da realidade. Petrópolis: Vozes.

Bonnewitz, P. (2003). Primeiras lições sobre a sociologia de Bourdieu. Petrópolis: Vozes.

Bourdieu, P. (1983). Questões de sociologia. Rio de Janeiro: Zero.

Bourdieu, P. (1989). O poder simbólico. Lisboa: Difel.

Bourdieu, P. (1995). Distinction. Cambridge: Cambridge University Press.

Bourdieu, P. (1996a). A economia das trocas lingüísticas. São Paulo: Edusp.

Bourdieu, P. (1996b). As regras da arte. São Paulo: Companhia das Letras.

Bourdieu, P. (1999). A dominação masculina. Rio de Janeiro: Bertrand Brasil.

Bourdieu, P. (2004). Coisas ditas. São Paulo: Brasiliense.

Bourdieu, P. (2005). Esboço de auto-análise. São Paulo: Companhia das Letras.

Bourdieu, P., \& Passeron, J. C. (1982). A reprodução. Rio de Janeiro: Francisco Alves.

Brito, M. J., \& Pereira, V. (1996). Socialização organizacional: a iniciação na cultura militar. Revista de Administração Pública, 30(4), 138-165.

Castro, C. (1990). O espírito militar: um estudo de antropologia social na Academia Militar das Agulhas Negras. Rio de Janeiro: Jorge Zahar.

DaMatta, R. (1996). Carnavais, malandros e heróis. São Paulo: Cortês.

Decreto n. ${ }^{\circ}$ 4.346, de 26 de agosto de 2002 (2002, agosto 27). Aprova o regulamento disciplinar do exército (R-4) e dá outras providências. Diário Oficial da União. Brasília, DF: Exército Brasileiro.

Foucault, M. (1987). Vigiar e punir: nascimento da prisão (5a ed.). Petrópolis: Vozes.

Goffman, E. (1971). As características de instituições totais. In A. Etzioni (Org.), Organizações complexas. São Paulo: Atlas.

Lei $n .^{\circ}$ 6.880, de 09 de dezembro de 1980 (1980, dezembro 11). Dispõe sobre o estatuto dos militares (E-1). Diário Oficial da União. Brasília, DF: Exército Brasileiro.

Leirner, P. (1997). Meia-volta, volver: um estudo antropológico sobre a hierarquia militar. Rio de Janeiro: FGV.

Maanen, J. van (1989). Processando pessoas: estratégias de socialização organizacional. In M. Fleury \& R. Fischer (Orgs.), Poder e cultura nas organizações (Parte I). São Paulo: Atlas.

Morgan, G. (1996). Imagens da organização. São Paulo: Atlas.

Wacquant, L. (2002). Corpo e alma: notas etnográficas de um aprendiz de boxe. Rio de Janeiro: Relumé-Dumará.

Wacquant, L. (2005). Habitus. In J. Beckert \& M. Zafirovski (Eds.). International encyclopedia of economic sociology. London: Routledge.

Weber, M. (2002). Ensaios de sociologia (5a ed.). Rio de Janeiro: LTC. 